\title{
WITTGENSTEIN SOBRE CERTEZA, REGRAS E NORMAS
}

\author{
Roberto Hofmeister Pich \\ Pontíficia Universidade Católica - RS
}

\section{INTRODUÇÃO*}

As notas de Ludwig Wittgenstein compostas em 1949-1951, compiladas e publicadas postumamente sob o título "Da certeza" ( $\ddot{\text { Uber }}$ Gewißheit) ${ }^{1}$, reconhecidamente atestam um Wittgenstein que, independentemente de admirar o caráter e o poder do filósofo e de ter se sentido deveras estimulado pelo "paradoxo de Moore" (PU 190-192), não ficou impressionado com as tentativas mooreanas de refutar o idealismo e/ou o ceticismo. Ao que tudo indica, os dois autores teriam discutido tais linhas de refutação em algum período anterior ${ }^{2}$, mas foi por ocasião de uma visita de Wittgenstein a Norman Malcolm, em Ithaca (New York), onde teriam discutido os ensaios de Moore Defense of Common Sense (1925) e, sobretudo, Proof of an External World (1939), na base, porém, do estudo Defending Common Sense, de Malcolm, que os temas do ceticismo e do fundamento do conhecimento voltaram a interessar Wittgenstein ${ }^{3}$. Assim, pois, a obra

\footnotetext{
* Este estudo foi originalmente publicado in: Helder Buenos Aires de Carvalho e Maria Cecília Maringoni de Carvalho (orgs.), Temas de ética e epistemologia, Teresina, Edufpi, 2011, p. 177199. Nessa que é, praticamente, uma reprodução, apenas modificações não substanciais foram feitas ao mesmo. Uma vez mais, creio que a sua publicação em outro veículo pode ajudar a divulgar os seus assuntos de debate e tornar mais acessível a sua utilização por quem o julgar útil.

${ }^{1}$ Sobre o contexto de surgimento da obra, cf. D. Moyal-Sharrock, Understanding Wittgenstein's On Certainty, p. 1-32 (Introdução e Capítulo 1). Cf. também M. Samures, Sobre Da certeza de Ludwig Wittgenstein. Um estudo introdutório, p. 10-29.

${ }^{2}$ Em 1929, em Cambridge.

${ }^{3}$ Cf. N. Malcolm, Nothing is Hidden: Wittgenstein's Criticism of his Early Thought, p. 201-235. Uma nota sobre esses assuntos, no que tange a Moore, pode ser lida em N. Malcolm, George Edward Moore, in: N. Malcolm, Knowledge and Certainty, p. 173-182.
} 
posteriormente intitulada "Da certeza" mostra influência tanto dos papers de Moore como das interpretações discutidas de Malcolm, ainda que, ao final, distancie-se do modo de abordagem - de refutação do ceticismo - desses dois autores ${ }^{4}$.

Há hoje certa concordância de que o tema do ceticismo, em $D a$ certeza, é abordado de modo muito particular por Wittgenstein, em se exigindo uma comparação, por exemplo, com as notas do Tractatus logico-philosophicus e, sobretudo, das Investigações filosóficas sobre o tema do conhecimento, assim como há contínuas discussões - e, atualmente, em maior e crescente número ${ }^{5}$ - se a atitude geral de aversão ao ceticismo, que Wittgenstein busca estabelecer, consegue mostrar-se competente nesse objetivo, ao serem consideradas versões "fortes" do ceticismo, tais como o ceticismo global ${ }^{6}$. De toda maneira, um aspecto que nem sempre tem sido percebido, naquelas pesquisas que se autocompreendem como expositivas da atitude desabonadora de Wittgenstein acerca do ceticismo, é que, ao oferecer um relato filosófico próprio sobre a "estrutura epistêmica dos jogos-de-linguagem" (M. Kober) em geral e, deve-se acrescentar, de alguns tipos de jogos-de-

${ }^{4}$ Cf. M. Kober, Certainties of a World-Picture: The Epistemological Investigations of On Certainty, in: H. Sluga and D. G. Stern (eds.), The Cambridge Companion to Wittgenstein, p. 411-413. Para a presente exposição, sobretudo na progressão dos tópicos, balizo-me - aqui, pois, declaradamente - neste estudo de M. Kober. Cf. também H. Sluga, Ludwig Wittgenstein: Life and Work - An Introduction, in: H. Sluga and D. G. Stern (eds.), The Cambridge Companion to Wittgenstein, p. 22-23.

${ }^{5}$ Um exemplo notável é todo um conjunto de estudos da obra organizada por D. MoyalSharrock, Readings of Wittgenstein's On Certainty, p. 142-274, com ensaios de A. Rudd, Th. Morawetz, D. Pritchard, M. Kober e E. Minar. Algo semelhante pode ser dito de D. MoyalSharrock (ed.), The Third Wittgenstein. The Post-Investigations Works, 2005. Cf. também D. Moyal-Sharrock, Understanding Wittgenstein's On Certainty, p. 157-201. Cf. ainda, em língua alemã, M. Kober, Gewißheit als Norm: Wittgensteins erkenntnistheoretische Untersuchungen in „Über Gewißheit“, 1993; H.-K. Kim, Gewissheit und Skeptizismus bei Wittgenstein, Neue Untersuchungen und Einsichten zu alten Zweifeln, 2006; A. Krebs, Worauf man sich verlässt Sprach und Erkenntnisphilosophie in Ludwig Wittgensteins , „Über Gewissheit“, 2007.

${ }^{6}$ M. Kober, Certainties of a World-Picture: The Epistemological Investigations of On Certainty, in: H. Sluga and D. G. Stern (eds.), op. cit., p. 412, não crê que a obra consiga cumprir esse propósito. Em uma proposta incomum, e que não será discutida neste breve estudo, R. Fogelin, Wittgenstein, p. 226-234, asseverou que o movimento filosófico com o qual a filosofia tardia de Wittgenstein mais se parecia, incluindo a obra última e inacabada Da certeza, seria, apesar de toda a aparência contrária do primeiro ao último dos seus escritos, o ceticismo pirrônico. Cf. também idem, Wittgenstein and Classical Scepticism, in: S. Shanker (ed.), Ludwig Wittgenstein. Critical Assessments, Vol. 2, p. 169-175. 
linguagem em particular - aqueles respectivos a usos e atitudes particularmente fundantes sobre o mundo exterior -, Wittgenstein acaba por teorizar novamente sobre a natureza das regras que constituem os jogos-de-linguagem ${ }^{7}$. Nesse sentido, o presente estudo deve ser visto como uma tentativa simples ${ }^{8}$ de estabelecer o próprio eixo norteador de uma obra wittgensteiniana que se apresenta como "epistemológica", sem, no entanto, sê-lo em sentido primário ou essencial: quer-se estabelecer o conceito mesmo de certeza, perseguindo a Consideração Final de que a sua categoria é lógico-linguística e só por esse motivo pode ele, em sentido secundário ou derivativo, servir para o inquérito da epistemologia, isto é, servir ao propósito de legitimar uma atitude de recusa ao ceticismo. Em outras palavras, quer-se aproximar a noção de "certeza" à noção de "regra" (e de "norma") dentro da referida obra (Divisões 2, 3 e 4) e perceber o que essa aproximação oportuniza para o entendimento da natureza da linguagem, e só então - o que, de início, pareceria mais óbvio - o que ela proporciona para um relato geral do conhecimento (Divisões 1 e 4). Em verdade, é precisamente na remodelação teórica da noção de certeza que o tema do ceticismo (sobre o mundo exterior) tem espaço de tratamento, para Wittgenstein, residindo no seguinte ponto de partida o seu distanciamento face à estratégia argumentativa adotada por G. E. Moore: da revisão da natureza da linguagem como uso à rejeição teórica do ceticismo a relação é boa.

\section{CERTEZA E CONHECIMENTO}

Primeiramente, proponho explorar a tese manifestamente defendida por Wittgenstein, em Da certeza, de que "conhecimento" e

\footnotetext{
${ }^{7}$ Cf. M. Kober, Certainties of a World-Picture: The Epistemological Investigations of On Certainty, in: H. Sluga and D. G. Stern (eds.), op. cit., p. 412. Cf., sobre o tema das "regras" e do "seguimento de regras", P. Boghossian, The Rule-Following Considerations, in: Mind, p. 507549; D. Bloor, Wittgenstein, Rules and Institutions, 1997 (sólida leitura "coletivista" daqueles temas); K. Puhl, Regelfolgen, in: E. von Savigny (Hrsg.), Ludwig Wittgenstein - Philosophische Untersuchungen, p. 122-142; G. Römpp, Ludwig Wittgenstein. Eine philosophische Einführung, p. 109-118. O locus classicus do conceito de regra é L. Wittgenstein, Philosophische Untersuchungen, $\S \S 80-86$, e o da noção de seguimento de regras é $\S$ 217-219.

${ }^{8}$ Como uma introdução aos problemas da abordagem wittgensteiniana sobre o conhecimento.
} 
“certeza" pertencem a diferentes "categorias" ( $\ddot{U} G$ 308). O proteico verbo "conhecer" (wissen) pode ser usado de muitas maneiras", para expressar alegações diversas, usos que, porém, ainda que admitam diferenças, parecem poder perfeitamente se cruzar ou justapor-se, como é simples perceber que alguém que alega "Eu sei que $X$ " pode também perfeitamente estar com isso dizendo "Estou convicto de que $X$ " ( $\ddot{U} G$ $18,176,181,591,620$ e muitos outros). O sentido contrastante interessante entre "conhecer" e "ter certeza" (sicher sein), entre "conhecimento" (Wissen) e "certeza" (Sicherheit, Gewißheit), porém, melhor aparece em casos de práticas expressando pretensões de conhecimento, para as quais, segundo critérios comuns aos envolvidos, podem ser pedidas e dadas "razões" (Gründe, Begründungen) ou então se admitem "certezas". Seja de que maneira "conhecimento" e "certeza" forem definidos, é inequívoco que, no sentido interessante à filosofia, não são "estados psicológicos" (Seelenzustände, innere Vorgänge) ou "sentimentos" afins (revestidos por palavras afins), que podem ser chamados de aspectos "subjetivos" inerentes às práticas respectivas ( $\ddot{U} G$ 38, 194, 308, 524, 563) ${ }^{10}$. "Saber” por “dar razões”, "ter certeza” e mesmo "duvidar" ou a "dúvida" (zweifeln, Zweifel) estão no domínio do "objetivo" e do "lógico", isto é, da impossibilidade do erro e da possibilidade do dar razões, da impossibilidade do erro e da impossibilidade do dar razões, da possibilidade tanto do dar quanto do pedir razões ${ }^{11}$ : todos esses, em particular a dúvida, estão no cerne de modos objetivos de comportamento ou de jogos-de-linguagem ( $\ddot{U} G$, 154, 231, 251-255, 333-334, 519).

Ao conhecimento vincula-se, pois, em especial, o tipo de prática que consiste em "dar razões”, a qual, como anota M. Kober com razão,

\footnotetext{
${ }^{9}$ Sobre os usos de "eu sei” ou "eu conheço" ("I know", "ich weiss") em Da certeza, cf. o estudo de Th. Morawetz, The Contexts of Knowing, in: D. Moyal-Sharrock and W. H. Brenner (eds.), Readings of Wittgenstein's On Certainty, p. 165-183.

${ }^{10}$ Os tópicos do "conhecimento objetivo" e da "certeza objetiva" são exaustivamente tratados por D. Moyal-Sharrock, Unravelling Certainty, in: D. Moyal-Sharrock and W. H. Brenner (eds.), Readings of Wittgenstein's On Certainty, p. 76-99.

${ }^{11}$ Cf. M. Kober, Certainties of a World-Picture, in: Hans Sluga and David G. Stern (eds.), op. cit., p. 413-414; A. Stroll, Why On Certainty Matters, in: D. Moyal-Sharrock and W. H. Brenner (eds.), Readings of Wittgenstein's On Certainty, p. 35ss.
} 
é "pública" ou é um jogo-de-linguagem "de uma comunidade"12. Nesse sentido, também aquilo que contemporaneamente se toma por "justificação" de uma crença de conteúdo proposicional sobre um aspecto do mundo deve ser entendido como uma atividade regida por regras e critérios apropriados a uma dada prática "epistêmica". Wittgenstein, a propósito, faz uso geral da expressão "justificação" (Rechtfertigung) como "dar razões”, tal como, na história da filosofia, em geral "dar razões" acompanha a pretensão de conhecimento proposicional ( $\ddot{U} G$ 192). O modo de justificar uma crença ou uma alegação de conhecimento deve atingir as exigências de um dado jogode-linguagem, podendo o próprio exercício de justificação variar, em grau de exigência, segundo a prática em questão - assim como, por exemplo, um jogo de justificação pode se vincular às regras e aos critérios de uma prática rigorosa e especializada da filosofia ou de uma prática de uma ciência da natureza, tal como a física por exemplo. Não há por que questionar que ${ }^{13}$ as regras e os critérios do justificar alegações de conhecimento não estão perenemente fixados e podem variar com o tempo, na história das comunidades de praticantes, assim como nas culturas, nas sociedades e, em especial, nas ciências ${ }^{14}$.

Efetivamente, é na consideração de práticas explicitamente "epistêmicas" - de alegar ou duvidar de algo, de argumentar acerca de algo, etc. - que, em Da certeza, "conhecimento" e "certeza” são distinguidos. Sejam quais exemplos possam ser seguidos ou construídos a partir das notas de Wittgenstein, jogos-de-linguagem epistêmicos têm, ao final, a seguinte descrição básica: “dar razões” de proposições conhecidas tem um fim, mas o fim do exercício de dar razões não são proposições verdadeiras que se revelam autoevidentes. O fim do jogo da "justificação da evidência" não é uma espécie de "visão" ou "intuição" (eine Art Sehen) da conexão de conceitos; antes, é "um modo de ação não-fundamentado" (eine unbegründete Handlungsweise), "o nosso agir [unser Handeln] que reside no fundo do jogo-de-linguagem” ( $\ddot{U} G$ 108,

\footnotetext{
${ }^{12}$ Cf. M. Kober, Certainties of a World-Picture, in: Hans Sluga and David G. Stern (eds.), op. cit., p. 414.

${ }^{13}$ Ao menos em muitos casos, ainda que não necessariamente em todos os casos.

${ }^{14} \mathrm{O}$ que é ratificado ao explorar-se a anterioridade da certeza a partir da reflexão sobre contextos e descrições do aprendizado da linguagem como uso (cf. abaixo sob 3).
} 
$110,204)^{15}$. A partir daí, apresenta-se um elemento central de uma teoria filosófica sobre o conhecimento, a justificação e a dúvida. Ora, na base do jogo- ou da prática-de-linguagem, em particular da prática epistêmica, em que, de fato, alegações de conhecimento podem, redutivamente e em cadeia, ser oferecidas para outras alegações de conhecimento, consta, por fim, justamente uma "certeza" ( $\ddot{U} G 115$, 192, 204, 232, 563). A certeza dentro de um jogo epistêmico específico (como seriam aquelas de um complexo de jogos em favor de uma alegação de conhecimento mais exigente) pode ser mostrada pelo nosso agir - ou nosso comportamento -, e como tal pode, na melhor hipótese, ganhar expressão através de sentenças, dado que certezas não são grandezas proposicionais ${ }^{16}$ ou ao menos (e indiscutivelmente) não são meras proposições empíricas. Em analogia apenas a determinadas proposições empíricas (cf. logo abaixo), na circunstância de alguém ser questionado se sabe ou não andar de bicicleta, acaba o jogo de pedir e dar razões, quando o questionado, insistindo no seu relato de que "Tais procedimentos e movimentos constituem o que é andar de bicicleta”, executa concretamente aquilo que foi solicitado. Se uma razão só pode ser dada dentro de um jogo - como o de comunicar-se sobre andar de bicicleta e/ou sobre o modo de pôr bicicletas em movimento -, a cadeia de razões chega a um fim tal como se chega à fronteira do jogo respectivo ( $\ddot{U} G 155,175,196,219-220)$. Em muitos casos, itens que

\footnotetext{
${ }^{15}$ Cf. M. Kober, Certainties of a World-Picture, in: Hans Sluga and David G. Stern (eds.), op. cit., p. 414-415. De que modo, nesses termos de "certezas", "razões" e "proposições conhecidas", a estrutura do conhecimento como crença justificada pode ser estabelecida, dado que parece haver, ali, em última análise um espaço para crenças não-inferenciais sobre o mundo, constitui um problema a parte; cf. sobre esse assunto R. Audi, Epistemology. A Contemporary Introduction to the Theory of Knowledge, Capítulo 7 ("The Architecture of Knowledge"), p. 184216, em que o autor, ademais, cf. id. ibid., p. 215, nota 11 (e também p. 207-208), alerta para o peso das certezas como forma de "metáfora fundacionista", nas práticas epistêmicas na obra $D a$ certeza.

${ }^{16}$ Esse ponto é explicitamente tematizado em M. Kober, 'In the Beginning was the Deed', in: D. Moyal-Sharrock and W. H. Brenner (ed.), Readings of Wittgenstein's On Certainty, p. 226-227, onde afirma, ao listar itens da descrição correta da prática de justificação, que: "3. The "chain of reasons (justifications, explanations, grounds)' comes to an end that can be characterized by a peculiar status within the 'logic' of the respective practice; the end, however, does not consist in true propositions that are specifiable in cognitive terms". Sobre a interpretação "proposicional" e a interpretação "não-proposicional" da natureza das certezas, cf. também E. Minar, On Wittgenstein's Response to Scepticism: The Opening of On Certainty, in: D. Moyal-Sharrock and W. H. Brenner (ed.), Readings of Wittgenstein's On Certainty, p. 253-260.
} 
podem ser chamados de amostras linguísticas de tais fronteiras novamente não as ações em si, que são inefáveis - reproduzem (e, por certo, expandem em número) "proposições mooreanas" ( $\ddot{U} G$ 111, 291, 448) ${ }^{17}$ : "A Terra é redonda", "Sei que eu jamais estive na lua", "A Terra existia há muito antes de eu nascer", "Esta é a minha mão”, etc. ${ }^{18}$.

Em segundo lugar, deve ser explicitamente enfatizado que aquilo que é considerado uma certeza, não sendo uma proposição ou asserção como tal, é antes a "competência" ou o "modo de ação" mesmo pelo qual uma dada sentença "está", indicando as fundações constitutivas de um dado jogo-de-linguagem. Em se admitindo o método de que os termos da epistemologia - do conhecimento do mundo exterior - só ganham conteúdo se analisados a partir do e dentro do jogo epistêmico, melhor ainda a partir de um "sistema" (System) residente na essência do argumento ou a partir do "elemento vital [Lebenselement] dos argumentos", as "certezas", em contraste às coisas conhecidas, porque justificadas, não têm de e nem são tipos de coisas ainda carentes de melhor definição - a serem conhecidas explícita e mesmo conscientemente. Antes, as "certezas", nem sequer são o enunciado que é o ponto de partida de um argumento, mas no máximo a "base" (Grundlage) do agir total ( $\ddot{U} G 105,360,410-411,414,446)$. Em seguida, deverá ser visto que esse mesmo "sistema" de certezas é possuído, em si não pelo indivíduo como tal, mas pela comunidade, e, a partir daí, pelo indivíduo em uma comunidade.

Em terceiro lugar, segundo a noção já assinalada de um jogo-delinguagem epistêmico metodicamente analisado, certezas de uma dada prática não podem ser justificadas dentro da mesma prática, visto que a sua "verdade", ali, é tida por certa, suposta a natureza mesma de um jogo-de-linguagem ${ }^{19}$. Se certezas são postas em dúvida em um jogo-delinguagem, o jogo-de-linguagem é em realidade outro, e as certezas são

\footnotetext{
${ }^{17}$ Sobre as "proposições mooreanas" em Da certeza, cf., por exemplo, E. Minar, Wittgenstein's Response to Scepticism: The Opening of On Certainty, in: D. Moyal-Sharrock and W. H. Brenner (eds.), op. cit., p. 253-260; A. Krebs, op. cit., p. 42-83.

${ }^{18}$ Aqui e adiante, nesta exposição, tais proposições não são exatamente reproduzidas, segundo conferimento rigoroso, mas só apresentadas de modo próximo o bastante, podendo diferir, de maneira não relevante, em formulação.

${ }^{19}$ Cf. M. Kober, Certainties of a World-Picture, in: H. Sluga and D. G. Stern (eds.), op. cit., p. 416.
} 
na realidade, ali, meras "pretensões de conhecimento". Não obstante isso, porém, também esse novo jogo de questionar pretensões de conhecimento ou de duvidar tem de pressupor alguma certeza ( $\ddot{U} G 54$ $56,155-156,232)$. Ora, se uma ação que constitui uma certeza de uma dada prática - como assinala a proposição "Eu tenho um corpo" ( $\ddot{U} G$ 258), em circunstâncias apropriadas de percepção visual e audição com respeito a uma comunidade de mesma língua - vem a ser posta em dúvida, deve haver motivos (eventualmente incomuns) por que aquela ação passa a ocupar, não mais o lugar da certeza, mas o de uma pretensão de conhecimento, em outra prática epistêmica. Por isso mesmo, na base de uma dada prática epistêmica, sempre é constitutiva ou logicamente impossível que um erro - não exatamente uma falsidade - esteja envolvido ( $\ddot{U} G$ 154-155). Dado que é logicamente impossível duvidar de uma certeza dentro de uma dada prática epistêmica, é automaticamente "absurdo" (Unsinn) duvidar de uma certeza dentro de uma dada prática epistêmica: Wittgenstein pode inclusive, a partir daí, afirmar que "há casos de tal tipo, em que, quando alguém dá sinais de dúvida, ali onde não duvidamos, não podemos entender, com segurança, os seus sinais como [reais] sinais de dúvida" ( $\ddot{U} G 154)$, e, "para que o ser humano se engane, ele já tem de julgar em conformidade com a humanidade” ( $\ddot{U} G 156)$, isto é, na base de alguma certeza; finalmente, "a pessoa racional [ou: razoável] não tem [em realidade] certas dúvidas” ( $\ddot{U} G 220$, bem como $333-334)^{20}$. Assim, pois, a partir dos três pontos ressaltados, conhecimento e certeza pertencem a diferentes "categorias" (Kategorien) "epistêmicas"21 pelo fato mesmo de o conhecimento se dar através de justificações e provas, tal que, em alguns casos, bastariam, diga-se, proposições autoevidentes e/ou analíticas, se essas fossem admitidas em absoluto, ou ter-se-ia provisoriamente - ou temporariamente - de argumentar em favor de

\footnotetext{
${ }^{20} \mathrm{O}$ que parece equivaler a dizer que, se a pessoa racional possui já sempre a linguagem e o comportamento respectivo, porque é competente para jogos-de-linguagem, há certezas que ela tem ou ao menos pode ter e dúvidas que ela em realidade ou em comportamento não tem e tampouco pode ter.

${ }^{21} \mathrm{E}$, antes disso, pertencem a duas categorias "gramaticais" (e constitutivo-objetivas) diferentes, como indicara $\ddot{U} G 308$, em que "a gramática em questão tem a ver com discurso e com usos de linguagem, ao invés de ter a ver com formas de palavras ou estruturas de frases", onde "certo" e "errado" seriam noções meramente descritivas; cf. N. Garver, Philosophy as Grammar, in: H. Sluga and D. G. Stern (eds.). The Cambridge Companion to Wittgenstein, p. 149-150.
} 
proposições cridas, dando razões gerais - e mesmo particulares - do tomar por verdadeiros certos objetos proposicionais. Por sua vez, a certeza em questão não tem justificação, mas é a condição de justificação e o fim do inquérito das razões $(\ddot{U} G 308)^{22}$.

Há discussão entre intérpretes sobre a possibilidade de ver nas certezas dos jogos, como um todo, tipos e papéis diferenciáveis, a saber, certezas de mais específicas e mutáveis até as mais universais e permanentes, tal que, vistas em um "sistema" maior, certezas explanariam não só a confiança comportamental com a qual práticas de linguagem contam, mas seriam também um fundo ou conjunto de práticas fundantes - antes constitutivas do que regulativas -, sem as quais jogo epistêmico qualquer pode haver logicamente. Caberia revisar e decidir, aqui, o papel que certas pseudoproposições empíricas, aparentes proposições empíricas ou sinais (apresentações) proposicionais empíricos(as) (Erfahrungssätze) exercem como eventualmente então como proposições "metodológicas"23 ou "gramaticais"24 (as proposições mooreanas reinterpretadas?) - ou então com respeito às "dobradiças" (hinges, Angeln; ÜG 341) ou "regras" da linguagem, isto é, da ação para com o mundo e as comunidades. Para todos os efeitos, mesmo sem maior especificação - "gramatical” ou também "proposicional” - dos tipos e papéis de tais dobradiças como "certezas" 25 , é possível lidar com a característica essencial das mesmas, a saber, que certezas, como os jogos-de-linguagem epistêmicos, cruzam-se e dão umas às outras mútuo suporte dentro de uma "imagem de mundo" (Weltbild) ${ }^{26}$. Bem explanada, pois, essa noção (cf. abaixo), tanto deve-se asseverar o papel fundante e irredutível das certezas nos jogos epistêmicos quanto anotar que, comparadas a um "sistema" ou "elemento vital” de argumentos, nada leva (claramente) a crer que, perguntada qual a família argumentativa à qual a noção

\footnotetext{
${ }^{22}$ Cf. M. Kober, Certainties of a World-Picture, in: H. Sluga and D. G. Stern (eds.), op. cit., p. 416-417.

${ }^{23}$ Cf. Th. Morawetz, The Contexts of Knowing, in: D. Moyal-Sharrock and W. H. Brenner (eds.), op. cit., p. 179-183.

${ }^{24}$ Cf. A. Krebs, op. cit., p. 47 ss.

25 Isso é exemplarmente feito por D. Moyal-Sharrock, Understanding Wittgenstein's On Certainty, p. 100-156.

${ }^{26}$ Cf. M. Kober, Certainties of a World-Picture, in: H. Sluga and D. G. Stern (eds.), op. cit., p. 417.
} 
wittgensteiniana de "justificação de evidência" ou de pretensões de conhecimento pertenceria, poderia ser apresentada aquela na forma de uma cadeia linear de razões ou de crenças simplesmente, ou mesmo de uma teia de motivos ou crenças conectadas - até mesmo de modos de ação fundantes racionalmente conectados. Como alguns estudos recentes mostraram, a "teoria da justificação de crenças" ou mesmo a "teoria do conhecimento" de Wittgenstein, incluindo a sua recusa ${ }^{27}$ via reflexão sobre condições de inteligibilidade - ao ceticismo clássico ou respectivo ao conhecimento empírico, não se deixa rotular nem como simples "fundacionismo" (em que o slogan seria "a cadeia de razões [crenças adotadas] chega a um fim") ${ }^{28}$ nem como tradicional "coerentismo" (ao qual serve o slogan do "sistema" ou de uma "teia" mais complexa e coerente de razões ou crenças sempre apoiadas em outras razões ou crenças) ${ }^{29}$. "Certezas" particularmente relevantes, que pertencem à essência dos argumentos empíricos e são de fato atestadas por Wittgenstein em certas passagens - $\ddot{U} G 105$, em especial $\ddot{U} G 225^{30}$ -, poderiam guardar certa semelhança estrutural com um sistema coerente, semelhança, porém, não defensável ao final. Ora, assim sugere M. Williams, se diante do "trilema de Agripa" para a justificação de crenças a opção teórica da epistemologia for o coerentismo, poder-se-á admitir, sim, contra o fundacionismo, que o acarretamento não-

${ }^{27}$ De fato, não uma refutação por meio de algo como uma "metafísica mais profunda"; cf. A. Rudd, Wittgenstein, Global Scepticism and the Primacy of Practice, in: D. Moyal-Sharrock and W. H. Brenner (eds.), Readings of Wittgenstein's On Certainty, p. 147.

${ }^{28}$ M. Williams, Why Wittgenstein Isn't a Foundationalist, in: D. Moyal-Sharrock and W. H. Brenner (eds.), Readings of Wittgenstein's On Certainty, p. 47-58, nega categoricamente que a teoria wittgensteiniana da certeza (epistêmica) preencha condições formais - sob os lemas "universabilidade", "especificabilidade", "autonomia" e "adequação racional" para definir "fundamento" - do fundacionismo epistêmico contemporâneo. A tipificação de um suposto "fundacionismo" da epistemologia da certeza, segundo Wittgenstein, é um dos objetivos centrais da obra importante de A. Stroll, Moore and Wittgenstein on Certainty, 1994, em especial p. 138159.

${ }^{29}$ Sobre essas duas direções teóricas básicas do relato filosófico sobre o conhecimento como justificação de crenças, cf., por exemplo, alguns dos ensaios (hoje clássicos) de E. Sosa, Knowledge in Perspective: Selected Essays in Epistemology, p. 65-85 ("Epistemology Today: A Perspective in Retrospect"), 108-130 ("Theories of Justification: Old Doctrines Newly Defined"), 149-164 ("The Foundations of Foundationalism") e 165-191 ("The Raft and the Pyramid: Coherence versus Foundations in the Theory of Knowledge").

${ }^{30}$ Cf. L. Wittgenstein, Über Gewißheit, § 225: "Aquilo em que estou firmado não é uma proposição, mas um ninho [Nest] de proposições”. 
inferencial de proposições empíricas particulares a partir de proposições "básicas" é vedado por Wittgenstein, ao suprimir ele tal base quando nota que a "interdependência" entre juízos básicos (certezas) e juízos empíricos não-básicos é "semântica". Se, com isso, o coerentista conclui que todo acarretamento epistêmico é, ao final, inferencial, ainda assim, em Da certeza, a "interdependência semântica é compatível com assimetrias justificacionais" - ou com incoerências entre os juízos que fazem chegar a uma dada crença ${ }^{31}$.

Adotando-se o método de análise da certeza até aqui, isto é, da natureza mesma do jogo-de-linguagem, em especial o epistêmico, ali notando a alegada diferença categorial, insinua-se como devido aprofundar o estudo da categoria-título - a certeza como o fundo de uma prática - através da aproximação entre jogo-de-linguagem, "forma de vida" e "imagem de mundo".

\section{CERTEZAS DE UMA COMUNIDADE LINGUÍSTICA}

Em nenhum momento de Da certeza Wittgenstein põe em suspeição a ideia de que as certezas de jogos-de-linguagem são certezas de uma comunidade, cujos membros estão envolvidos nas práticas e no aprendizado da linguagem ( $\ddot{U} G$ 279-286). Essa constatação, ligada à acepção de que toda certeza, como princípio de uma prática, é "ação" ou "modo de ação" ( $\ddot{U} G$ 204, 402), motiva intérpretes a explanar a "certeza" em associação à noção de "forma de vida" (Lebensform) noção, a propósito, predominante nas Investigações filosóficas e utilizada sem destaque em Da certeza $(\ddot{U} G 358)^{32}$. Por que, pois, essa associação? Pode-se contar, para o propósito de entendê-la, com uma explícita definição de "forma de vida"? Em verdade, como nota M. Kober, é embaraçoso que nem mesmo para "jogo-de-linguagem" Wittgenstein fornece uma definição clara, mas apenas traços gerais, com exemplificações (PU 2, 8, 258): jogo-de-linguagem vem a ser "o

\footnotetext{
${ }^{31}$ Cf. M. Williams, Why Wittgenstein Isn't a Foundationalist, in: D. Moyal-Sharrock and W. H. Brenner (eds.), op. cit., p. 55.

${ }^{32}$ Cf., por exemplo, M. Kober, Certainties of a World-Picture, in: H. Sluga and D. G. Stern (eds.), op. cit., p. 417ss.; D. Moyal-Sharrock, Understanding Wittgenstein's On Certainty, p. 6-7, 97-98, 152-156.
} 
processo todo de usar palavras”, incluindo nisso, na verdade, tanto a linguagem quanto as ações de que a vida está constituída $(P U 7)^{33}$, em que o usuário exibe para com os demais, não a posse e o domínio de itens de linguagem com propriedades ou traços de definição comuns, mas a posse e o domínio desses itens com "semelhança(s)-defamiliaridade" (Familienähnlichkeit, $P U$ 65-71) que se sobrepõem ${ }^{34}$. Reconhecidamente, "jogo-de-linguagem" é expressão cunhada para destacar o fato de que o realizar concreto de uma prática linguística (das Sprechen der Sprache) faz parte de uma forma de vida (PU 23!) ${ }^{35}$. Daí que "forma de vida" pode ser tomada como "uma pluralidade de jogos-de-linguagem", "uma rede complexa de similaridades, justapondose e cruzando-se” ( $P U$ 66) - não necessariamente compondo uma estrutura sistêmica em sentido estrito, perfazendo antes algo como uma "guirlanda de práticas" (garland of practices, M. Kober) "que se apoiam e complementam mutuamente" 36 . Novamente, forma de vida requer ou tem como elemento constitutivo uma comunidade linguística ou a vida de uma comunidade ${ }^{37}$. Certezas, tal como eixos, nem se originam nem se localizam nem têm constituição ou caracterização possível fora ou independentemente daquele mesmo entorno vivo e dinâmico (cf., por exemplo, $\ddot{U} G$ 151-152).

E é também com respeito à comunidade ou ao todo dos usuários e usos da linguagem que deve ser localizado o conceito chave de $D a$ certeza, isto é, "imagem de mundo" (Weltbild) - só em aparência substitutivo de "forma de vida", uma vez que ele, em si, e de um modo que não se observa claramente em "forma de vida", pertence à dimensão das “certezas”, e não das "práticas” ou dos “jogos” como um

${ }^{33}$ Cf. M. Kober, Certainties of a World-Picture, in: H. Sluga and D. G. Stern (eds.), op. cit., p. 417-418.

${ }^{34}$ Cf., por exemplo, G. P. Baker and P. M. S. Hacker, Essays on the Philosophical Investigations Volume 1 - Wittgenstein: Meaning and Understanding, p. 190-194 (X - Family Resemblance, p. 185-208).

${ }^{35}$ Esse ponto também foi enfatizado por M. B. Hintikka und J. Hintikka, Untersuchungen zu Wittgenstein, p. 280-281, contra o equívoco de uma interpretação de jogos-de-linguagem - e da linguagem com uso - meramente em termos de "jogos-de-linguagem verbais".

${ }^{36}$ Cf. M. Kober, Certainties of a World-Picture, in: H. Sluga and D. G. Stern (eds.), op. cit., p. 418.

${ }^{37}$ Cf. H.-J. Glock, Wittgenstein Dictionary, p. 124-129. Um comentário geral - mas de contexto - sobre "forma de vida" na obra wittgensteiniana pode ser encontrado no trabalho de G. L. Daldegan de Pádua, O conceito de regras em Da Certeza: terceiro Wittgenstein?, p. 46-49. 
todo. Exatamente assim ele opera como um "tipo de mitologia" (eine Art Mythologie) e desempenha - ou simboliza - o papel de "regras de jogo" (Spielregeln; $\ddot{U} G 95)^{38}$. Não sendo exatamente uma concepção sobre o mundo, Weltbild, como o mito e as suas características, antes aponta para o modo como regras não expressas de um jogo fundam um jogo: é um arcabouço cuja "correção" (Richtigkeit) não é medida, pois é o meio pelo qual se estabelece "correção", guiando o comportamento linguístico como o "pano de fundo transmitido" (der überkommene Hintergrund, ÜG 94). Agir segundo a forma do "mito" mostra uma rede de "decisões" (Entscheidungen) e "convicções" (Überzeugungen) de ação, não primariamente a verdade "objetiva” ou "desvinculada" daquilo de que os praticantes se encontram convencidos. Nesse ponto, a analogia do mito permite visualizar a imagem de mundo como descritiva da "base" ou do "fundamento óbvio" (selbstverständliche Grundlage, $\ddot{U} G$ 167) da comunidade relacionada com o mundo. Novamente, deveria haver espaço para discriminar, no Weltbild, tipologias de "dobradiças", cujos sinais linguísticos são certas "proposições de experiência"

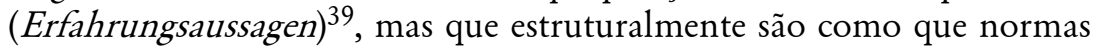
de ação ou reação ao mundo, em comum, assumindo papéis de condição de possibilidade da linguagem como uso ( $\ddot{U} G$ 165-167). Que o próprio Wittgenstein alcançou formulações fortes para essa dimensão de uma rede de convicções de ação fundantes, verifica-se na insistência com que fala da imagem de mundo como constituindo "o substrato de todo o meu investigar e asseverar" (das Substrat alles meines Forschens und Behauptens), e as quasi sentenças que o descrevem ${ }^{40}$ não são todas

${ }^{38}$ Cf. também J. Schulte, Within a System, in: D. Moyal-Sharrock and W. H. Brenner (eds.), Readings of Wittgenstein's On Certainty, p. 61s.

${ }^{39}$ Em uma exposição instigante, J. A. Giannotti, Apresentação do mundo. Considerações sobre o pensamento de Ludwig Wittgenstein, p. 244-245, parece falar desse tipo de proposição como de "proposições polares"; em verdade, J. A. Giannotti estabelece, segundo o papel de desempenho, uma distinção tripla entre "proposição de essência" ("quando descreve a regra"), "proposição bipolar" ("quando é capaz de dizer sim ou não a um fato" e de "determinar o estatuto do erro") e "proposições polares" ("quando expressam, muitas vezes tacitamente, os indubitáveis necessários a essa prática"). A meu juízo, porém, o vínculo entre "regras" e "certezas" (sendo estas regras assim entendidas porque em desempenho em um jogo epistêmico), não está, ali, claramente desenvolvido.

${ }^{40}$ Descrevem-no, mas não equivalem a ele, pois modelos de ação ou reação de indivíduos em comunidade são indizíveis. 
igualmente passíveis de tornarem-se sujeitas a reais jogos epistêmicos de teste ( $\ddot{U} G 162-164,233-234,281-284)^{41}$.

Características da imagem de mundo servem também às regras de ação constituintes da mesma: sendo uma rede de diferentes modos de ação - cf. $\ddot{U} G$ 274, em que se fala de um "conjunto de proposições conectadas” ensinadas pela experiência não isoladamente -, (i) o Weltbild não tem de ser um sistema "inventado" em seguimento a critérios e semelhante a uma “crença científica” ( $\ddot{U} G$ 167, 234-236), embora ele possa implicar práticas como teorias científicas, bem como práticas filosoficamente refletidas, etc., calcadas em "certezas" fundantes afins $^{42}$. Um Weltbild, entretanto, não tem de ser assim, pois não há um tipo especial de modos de ação e de práticas que tem de lhe dar constituição. Portanto, é só enquanto calcado em "certezas” em um sentido geral não justificáveis e "primitivas" que o Weltbild pode ser tomado como um "corpo de conhecimento" (Wissenskörper, ÜG 288). (ii) Ademais, a imagem de mundo assemelha-se a um "epifenômeno" (minha expressão) de um fenômeno natural - no sentido de culturalantropológico -, a saber, aquelas experiências (Erfahrungen) comuns e partilhadas ( $\ddot{U} G 274-275,281$ ), as quais ganham voz, por exemplo, nas "proposições mooreanas" (cf. acima). Não é a imagem de mundo, portanto, que tem espaço descritivo primário - ou função explanatória - na linguagem como uso, mas as ações fundantes e intuições comuns partilhadas pelas pessoas de uma dada comunidade ${ }^{43}$. Nesse sentido, "A Terra já existia há muitas centenas de anos antes de eu nascer”, uma atitude ou um ponto de partida compartilhado a partir do aprendizado tácito e/ou treinamento ${ }^{44}$ e que está drasticamente inserido em inúmeras das - eventualmente em todas as - práticas linguísticas respectivas ao mundo exterior, mesmo que, na prática (epistêmica) da

\footnotetext{
${ }^{41}$ Cf. M. Kober, Certainties of a World-Picture, in: H. Sluga and D. G. Stern (eds.), op. cit., p. 418-419.

${ }^{42}$ Id., ibid., p. 420.

${ }^{43}$ Mesmo quando age sobre elas, o Weltbild, em última análise, interage com elas e depende delas - em analogia ao que "forma de vida" é para jogos-de-linguagem, "imagem-de-mundo" é um emblema de algo estabelecido anteriormente.

44 A tipificação de pontos de partida ou dobradiças do sistema, essencialmente não proposicionais, em obediência a uma descrição do seu modo de aquisição, foi buscada por A. Stroll, Moore and Wittgenstein on Certainty, p. 158, de acordo com os lemas "instinto", "ação" e "treinamento".
} 
linguagem, possa ser igualmente um conteúdo proposicional empírico, é uma atitude pré-discursiva fundamental que possibilita jogos-delinguagem. Ela se encontra junto com diversas outras acepções empíricas gerais do modo como os seres humanos agem e a partir das quais têm ou conseguem ter crenças empíricas e julgar sobre "diferentes estados de coisas" ( $\ddot{U} G$ 146, 410-411). Aquela mesma pode servir como uma "imagem simples" (einfaches Bild) da qual não cabe duvidar ( $\ddot{U} G$ 147). "Imagens" e "dobradiças" simples como aquela parecem estar mesmo na base profunda ${ }^{45}$ de outras que, em conjunto, constituem a nossa "imagem de mundo". Em passagens diversas de Da certeza, Wittgenstein alerta, pois, para o papel - já aludido, anteriormente, a silentio - hoje chamado de Doppelgänger de determinadas sentenças, não tendo de expressar conhecimento proposicional empírico, mas sinalizando uma atitude aprendida de consideração empírica ${ }^{46}$.

Para o fundo epistemológico da obra em análise, mas fugindo ao propósito deste estudo sobre os elementos do conceito de certeza, segundo Wittgenstein, é uma pergunta central se, para todo e qualquer Weltbild, há certezas-dobradiças que operam como "condições de possibilidade" universais e que são "imprescindíveis" (ungiveupable) 47 para estabelecer jogos-de-linguagem em geral, como, por exemplo, "A Terra já existia há muitas centenas de anos antes de eu nascer" e "Eu tenho um corpo". Se a resposta for positiva, certezas wittgensteinianas não apenas em nada se relacionam, essencialmente, com proposições assumidas "como estando além da dúvida razoável”, por causa da sua relação "com condições privilegiadas de percepção" (sentenças protocolares) e tampouco com "instâncias não proposicionais do imediatamente 'dado", tal como dados sensórios ou objetos físicos ${ }^{48}$; antes, as certezas wittgensteinianas se prestam a uma leitura

\footnotetext{
${ }^{45}$ Sobre a tese da prioridade de certas "dobradiças", cf. D. Moyal-Sharrock, Understanding Wittgenstein's On Certainty, p. 150-152.

${ }^{46}$ Cf. D. Moyal-Sharrock, Unravelling Certainty, in: D. Moyal-Sharrock and William H. Brenner (eds.), Readings of Wittgenstein's On Certainty, p. 90, 95.

${ }^{47}$ Cf., sobre isso, D. Moyal-Sharrock, Understanding Wittgenstein's On Certainty, p. 106-107.

${ }^{48}$ Cf. M. Kober, 'In the Beginning was the Deed', in: D. Moyal-Sharrock and W. H. Brenner (eds.), op. cit., p. 225.
} 
transcendental da representação, da linguagem e do conhecimento ${ }^{49}$. A obra Da certeza poderia ser lida, portanto, como admitindo a conclusão de que certas regras, no fundo dos jogos e das práticas, incluindo as práticas epistêmicas, estão além - ou aquém - da notória mutabilidade $^{50}$ de imagens-de-mundo, as quais são complexas e, por natureza, posteriores aos modos de ação. $\mathrm{Na}$ presente seção, buscou-se simplesmente estabelecer a anterioridade lógico-linguística das certezas.

\section{ANTERIORIDADE LÓGICO-LINGUÍSTICA E EPISTÊMICA DA CERTEZA E DESCRIÇÕES DE APRENDIZADO}

Tendo sido estabelecido que "certeza", diferentemente de "conhecimento", não é nem fundamentada nem justificada, a abordagem wittgensteiniana do conhecimento insiste no método de considerar problemas epistemológicos somente junto com pareceres sobre a natureza da linguagem - em especial sobre a linguagem como uso ( $\ddot{U} G 306,472$ ), a ponto de poder-se dizer: "[...] o conceito de conhecer está engatado com o de jogo-de-linguagem” ( $\ddot{U} G$ 560). Para entender, portanto, o que a linguagem como linguagem de uso é - e isso vale para a certeza que está na base do jogo-de-linguagem -, há uma tendência clara, em Wittgenstein, de analisar o "momento" ou a "circunstância" em que se adquire a linguagem ou as regras, em que se aprende a falar ou a compreender os jogos linguísticos. A analogia do ensinar e do treinar alguém para possuir o know-how do emprego de regras é um meio para descrever o emprego e a posse de regras. Esse modo analógico de estudo das regras liga argumentativa e tematicamente Da certeza com as Investigaçôes filosóficas. Ele é o modo argumentativo, ademais, que põe em evidência a equiparação das "certezas" das práticas da linguagem - também as epistêmicas, sobre o mundo exterior - com as "regras constitutivas" da linguagem.

\footnotetext{
${ }^{49}$ Sobre a leitura transcendental das certezas e do Weltbild, cf., por exemplo, W. H. Brenner, Wittgenstein's 'Kantian Solution', in: D. Moyal-Sharrock and W. H. Brenner (eds.), Readings of Wittgenstein's On Certainty, p. 122-141.

${ }^{50}$ Cf. M. Kober, Certainties of a World-Picture, in: H. Sluga and D. G. Stern (eds.), op. cit., p. 430-436.
} 
Antes disso, porém, ressalte-se que, se as analogias do ensinar e do treinar são elucidativas das origens das "certezas" e, daí, das práticas, são em particular um esboço para uma teoria geral da origem das "regras". A chave interpretativa tanto da origem de regras quanto da origem de certezas, assim se notará, é o princípio da ação. Passagens como $\ddot{U} G 475$ evidenciam que a visão wittgensteiniana do comportamento linguístico é quase primitivista ${ }^{51}$ - como o do ser humano animal, instintivo, independentemente de "raciocínio". Aqui, há um espaço para conceber o princípio da ação como a posse e a execução de "habilidades inatas" e do "instinto" de "reconhecer regularidades" tanto do mundo quanto do comportamento alheio ${ }^{52}$. Assim se dá na reação das crianças face ao mundo, à comunidade e ao comportamento dos adultos. A ação dos agentes aprendizes para com o mundo e para com os outros é de confiança instintiva. Por isso mesmo, o contexto de ensinar-treinar, aprender, imitar e tornar-se membro apto na comunidade linguística tem no seu fundamento a ação conforme a isto é: conforme ao que é externamente exigido, porque adotado 53 . Ora, a forma do jogo-de-linguagem, sob a perspectiva da origem, é que, no jogo, se age em conformidade com. Ali, há um treino instintivo de agir de determinada maneira ou de reagir a um sinal externo de determinado modo, "determinado modo" esse que pressupõe a existência de uma regra, de um "uso regular" (ein ständiger Gebrauch),

\footnotetext{
${ }^{51}$ Aqui, o vínculo entre o "primitivo" e o "etnológico" parece ainda mais forte do que aquele que pode ser constatado nas Investigações filosóficas; cf. S. Cavell, Notes and Afterthoughts on the Opening of Wittgenstein's Investigations, in: H. Sluga and D. G. Stern (eds.), The Cambridge Companion to Wittgenstein, p. 288: "(The primitive is in principle a far more important theme to work out for the Investigations (...). It would require accurately characterizing one's sense of the ethnological perspective Wittgenstein characteristically takes toward human kind as such)".

${ }^{52}$ Cf. M. Kober, Certainties of a World-Picture, in: H. Sluga and D. G. Stern (eds.), op. cit., p. 420s. Sobre esse ponto, sugiro a leitura de R. Rhees, Wittgenstein's On Certainty: There - Like our Life, p. 93-105. Cf. também D. Z. Phillips, Wittgenstein's On Certainty: The Case of the Missing Propositions, in: D. Moyal-Sharrock and W. H. Brenner (eds.), Readings of Wittgenstein's On Certainty, p. 20s.

${ }^{53} \mathrm{Cf}$. S. Cavell (falando sobre as Investigações filosóficas), Excursus on Wittgenstein's Vision of Language, in: S. Cavell, The Claim of Reason, p. 178: "Instead, then, of saying either that we tell beginners what words mean, or that we teach them what objects are, I will say: We initiate them, into the relevant forms of life held in language and gathered around the objects and persons of our world. For that to be possible, we must make ourselves exemplary and take responsibility for that assumption of authority; and the initiate must be able to follow us, in however rudimentary way, naturally (...); and he must want to follow us (...)".
} 
com o qual se entra em conformidade (PU 198, também PU 199). Crianças são a imagem própria da origem da aquisição de um jogo-delinguagem: de um reagir não duvidando em absoluto, mas aprendendo ou sendo treinado, agindo conforme a. Em se cumprindo essa condição, há absorção instintiva da regra que rege o jogo, e a dúvida está logicamente excluída ( $\ddot{U} G$ 283). Nessas reflexões de origem, portanto, a natureza mesma da linguagem como uso aparece: a origem e a forma básica do jogo-de-linguagem é uma reação. Só a partir daí formas mais complexas de jogos podem surgir. A relação lógica entre $O$ reagir originário e o aprimoramento da linguagem é de anterioridade e posterioridade ( $\ddot{U} G$ 535-538). Logicamente, ou, segundo a natureza mesma da linguagem como uso, a dúvida só pode ser posterior, ela só pode vir após alguma crença ou confiança ( $\ddot{U} G 150,159-160,472,519$, 538). Daí a tese de que "a forma primitiva do jogo-de-linguagem é a certeza"54: somente se há certeza, há jogo-de-linguagem. Afinal, por definição, não pode dar-se que a incerteza esteja no princípio, pois uma incerteza não leva instintivamente à ação/reação - e que a ação/reação está no princípio do jogo linguístico, isso é inquestionável ( $\ddot{U} G$ 143144, 402).

A lição dos contextos de ensinar/treinar e adquirir o jogo-delinguagem a partir da ação fundante parece forçar a admissão de que a linguagem contém regras constitutivas de jogos primários, as quais são elas mesmas dotadas de anterioridade lógica. É evidente que aprendizados posteriores podem transformar o caráter de certezas em meras pretensões de conhecimento - como o conteúdo expresso em "A Terra gira ao redor do sol”. E certezas podem também ser posteriormente adquiridas. Se “dobradiças" são e podem ser "adquiridas" - jamais gozando necessariamente de "evidência” -, (algumas e/ou muitas delas) são por isso mesmo "prescindíveis" Sobretudo a educação e a infusão teórica (por meio das ciências) de

\footnotetext{
54 A passagem de Wittgenstein provém de Ensejos filosóficos (Philosophical Occasions, Vermischte Bemerkungen), apud Cf. M. Kober, Certainties of a World-Picture, in: H. Sluga and D. G. Stern (eds.), op. cit., p. 421-422. Cf. também N. Malcolm, Wittgenstein: The Relation of Language to Instinctive Behaviour, in: S. Shanker (ed.), Ludwig Wittgenstein. Critical Assessments, Vol. 2, p. 305-306, 313ss.

${ }^{55}$ Cf. sobre isso novamente D. Moyal-Sharrock, Understanding Wittgenstein's On Certainty, p. 106-107 e 143-147.
} 
certezas podem desabonar certezas. Antes e depois, seguem havendo certezas adquiridas só por instrução - aquelas que, diferentemente de outras ("universais" sobretudo enquanto "naturais" ou "instintivas" como "Eu tenho um corpo", "Esta é a minha mão", etc., nunca ingressantes no jogo da justificação), são mutáveis (como "A Terra é redonda") ${ }^{56}$. Em realidade, formas de "reflexão" impulsionadas por educação e teoria apontam, em si mesmas, para jogos-de-linguagem complexos - mas têm de ter, não obstante isso, também eles uma certeza, a cada vez, na sua base. Reconhecidamente, a dúvida, uma prática epistêmica cuja regra de realização tem de ser uma certeza, só pode ser posterior a jogos e regras mais primitivas. Independentemente do mérito de uma "taxonomia" (minha expressão) de certezas, há que se admitir, pois, a ideia de uma hierarquia de primitividade e de prevalência tanto entre regras quanto entre jogos de linguagem ( $\ddot{U} G$ $317,380,415-416)^{57}$. Os relatos de origem, portanto, reforçam o retorno da linguagem e da imagem-de-mundo à habilidade de agir em conformidade aos sinais da comunidade, de modo que "certezas" tanto são regras quanto não são essencialmente proposições - ainda que derivativamente tenham de sê-las ou de gerá-las.

${ }^{56}$ Cf. id., ibid. A uma hierarquia e taxonomia de certezas pode-se associar outro termo delineador da anterioridade e posterioridade das mesmas, a saber, o "primitivo". Diferentemente do que fez a pesquisa recente orientada em Da certeza, o próprio Wittgenstein pouco explicitou a distinção entre o "primitivo" e o "complexo" ou "refinado" no que concerne a certezas e práticas de linguagem. Mas, como detalhou a pesquisa de M. Kober, pode-se ler na obra de Wittgenstein não apenas uma noção de "primitivo" que ressalta que uma certeza é uma regra constituinte como saber agir (know-how), portanto, regra constituinte de um jogo. Antes, o autor também apontou com razão ao fato de que "primitivo" pode ser (i) "fundamental", "original", "infundado", mesmo "não justificável" (ÜG 475), podendo ser ainda (ii) "simples", "comum" ou "cotidiano", simplesmente "familiar" a todo membro da comunidade - nada impedindo que uma dada certeza cubra os dois aspectos e devendo-se considerar ainda certa dificuldade em distinguilos ( $\ddot{U} G$ 673). Cf. M. Kober, Certainties of a World-Picture, in: H. Sluga and D. G. Stern (eds.), op. cit., p. 422-423. Isso estabeleceria, pois, algo como uma distinção entre primitividade "estrita" e primitividade "comum", possivelmente entre (definitiva) imunidade à dúvida razoável e vulnerabilidade ao processo de dar razões (em boa medida, estando ainda aquela muito determinada por cada comunidade e condicionada à cultura e ao tempo; cf. $\ddot{U} G$ 155-156, 314 315). Isso não mudaria, porém, o fato de que "certeza" é regra constituinte de prática de linguagem, graduável segundo primitividade e/ou aquisição refletida, dado o contexto epistêmico em que se fez o questionamento por razões.

${ }^{57}$ Cf. D. Moyal-Sharrock, Understanding Wittgenstein's On Certainty, p. 100-116. 
A presente seção da exposição, pois, teve o objetivo de fazer perceber que, pelo método da análise do jogo-de-linguagem nos relatos de origem, a anterioridade da certeza pode ser estabelecida pelo delineamento da sua primitividade - diferenciável ou graduável. Esse item se mostra potencialmente profícuo no contexto do debate com o ceticismo sobre o mundo exterior. Deve ser marcada, ademais, a natural e reiterada equiparação de "certeza” à "regra".

\section{REGRA E NORMA}

Através do mesmo método de análise da prática da linguagem, a categoria da certeza pode, agora, ganhar precisão final. Certezas são regras. Avaliar "regras" por meio das variações sobre o tema "certeza" redimensiona também o papel das "regras” na explanação da natureza da linguagem. Que certezas são regras é uma convicção que perpassa o debate, na pesquisa, quanto à dupla função de expressões proposicionais como aquelas tipificadas pelas proposições mooereanas - "A Terra já existia há muito antes de eu nascer", "Esta é a minha mão”, etc. -, isto é, a de aparentes proposições empíricas com valor de verdade e, por outro lado, a de "padrão de racionalidade" 58 . Ora, se essas amostras de tais atitudes são conduzidas por Wittgenstein aos papéis assumidos por componentes em práticas de linguagem sobretudo epistêmicas ou discursivas -, certezas são sempre regras, e não pretensões de conhecimento, e regras que possibilitam o jogo de justificar pretensões: dão limites ao jogo (aos seus movimentos) tal como regras constitutivas e, portanto, definem-no: "a indubitabilidade [Zweifellosigkeit] pertence à essência do jogo de linguagem” ( $\ddot{U} G$ 370, também 391-394, 456-458). São para ele (seja ele, na imagem-de-mundo, mais ou menos fundamental), no caráter de uma regra que expressões proposicionais como "Esta é a minha mão" ou "Eu tenho um corpo"

\footnotetext{
${ }^{58}$ Comparando-as às regras lógicas e matemáticas, em seu "estatuto lógico peculiar", W. Child, Wittgenstein, p. 210ss., 214, vê nas certezas, que identifica com as "proposições mooreanas", o papel de "regras de investigação" do mundo exterior ou de regras que governam "a descrição correta do mundo empírico".
} 
apenas sinalizam, uma condição de possibilidade ${ }^{59}$. Mudar ou abandonar regras implica, rigorosamente, mudar ou abandonar um dado jogo ( $\ddot{U} G$ 61-64). Sendo o que são, há o jogo que as regras/certezas constituem. O que é constitutivo não é justificado nem justificável dentro do próprio jogo, tampouco é falso ou verdadeiro; mas, com aquilo (por exemplo, "A Terra existia há muito antes eu nascer") os passos do jogo (por exemplo, o estudo geral da história ou dos fatos e acontecimentos do passado) são justificados e justificáveis ( $\ddot{U} G$ 187192), pertencendo esses à categoria do que é falso ou verdadeiro. A certeza não é fundada, mas funda; só o que é fundado pode ser verdadeiro ou falso, certo ou errado ( $\ddot{U} G 205,494-497)^{60}$.

Neste ponto, pode-se enfim ratificar que a noção de certeza, para Wittgenstein, é primariamente lógico-linguística: ela é ao menos um tipo dentro de uma possível e larga tipologia de regras constitutivas de jogos, ainda que seja igualmente simples pensar que todas as regras são certezas, porque operam como "saber-como" (know-how), cuja posse insere um indivíduo em certa prática de linguagem. Essa equiparação, a partir de $D a$ certeza, ficaria apenas ofuscada pela compreensível tendência de Wittgenstein, ali, de voltar-se a atitudes fundantes em jogos epistêmicos suscitados, as quais gradualmente tiram as condições de possibilidade ou o espaço lógico do jogo da dúvida cética sobre a existência do mundo exterior. Notar que Wittgenstein buscava em $D a$ certeza, via análise da natureza da linguagem, tipos de certeza que tornam nonsense ${ }^{61}$ a permanência do jogo cético é mérito da análise e

${ }^{59}$ Cf. L. Wittgenstein, Über Gewißheit, § 371: "Não significa "Sei que isso é uma mão" no sentido de Moore o mesmo ou algo semelhante a: eu poderia fazer uso de sentenças como "Tenho dores nesta mão" ou "Esta mão é mais fraca do que a outra" ou "Uma vez fraturei esta mão" e de inúmeras outras em jogos-de-linguagem, nos quais não tem lugar uma dúvida da existência desta mão?".

${ }^{60}$ Cf. M. Kober, Certainties of a World-Picture, in: H. Sluga and D. G. Stern (eds.), op cit., p. 424-425. Sobre o conceito de verdade no Wittgenstein tardio, cf. id., ibid., p. 427-430.

${ }^{61}$ Em que, com efeito, o sentido "negativo" fundamental de "absurdo" (nonsense) estaria sendo respeitado, como aquele que, de resto, C. Diamond, What Nonsense Might Be, in: C. Diamond, The Realistic Spirit. Wittgenstein, Philosophy, and the Mind, p. 106, identifica para a filosofia de Wittgenstein como um todo: "[...]: for Wittgenstein there is no kind of nonsense which is nonsense on account of what the terms composing it mean - there is as it were no 'positive' nonsense. Anything that is nonsense is so merely because some determination of meaning has not been made; it is not nonsense as a logical result of determinations that have been made". 
classificação das certezas como "dobradiças" feitas por Danièle MoyalSharrock ${ }^{62}$.

É ainda importante ressaltar que, se justificar uma pretensão de conhecimento a partir de certezas equivale a justificar a prática de certos movimentos "prescritos", há um bom sentido para dizer-se que certezas são "normas constitutivas" ( $\ddot{U} G 473)$ - porém, em um sentido epistêmico, e não deôntico, em que "prescritividade" é explanada melhor por "normatividade" do que por regramento ${ }^{63}$. Em verdade, o próprio Wittgenstein alerta ao fato de que, de certas proposições empíricas, pode-se mudar a sua forma (ou o seu caráter) proposicional em uma "norma de descrição" (Norm der Beschreibung, ÜG 167, 318$321,634)^{64}$ - servindo, em Da certeza, as expressões "proposição metodológica" (methodologischer Satz), "proposição da lógica" (Satz der Logik) e "regra" (Regel) ao mesmo propósito teórico, e ainda, em Reflexões sobre os fundamentos da matemática, a expressão "regra gramatical" (Regel der Grammatik). Nesse caso, faz-se daquilo que, no meio descritivo da linguagem, é uma proposição empírica, uma "norma" (Norm). O uso de "norma" para aquilo que é constitutivo de um jogo-de-linguagem não é tão frequente como o uso de "regra". Há, entretanto, autores, como M. Kober, que, atentando ao que parece ser uma variante adicionada por Wittgenstein ao manuscrito, sugerem a adoção preferencial de "norma", com a vantagem de que "norma" comporta, para a certeza wittgensteiniana, a "ambiguidade sistemática" de gerar os adjetivos "normal" e "normativo". Se "normal" admite uma força descritiva, aplicando-se a sentenças que enunciam o que é o "normal" humano, o adjetivo "normativo" comporta claramente o sentido constitutivo ou prescritivo, indicando a competência de uma

\footnotetext{
${ }^{62}$ Cf. nas Referências Bibliográficas e, em especial, Understanding Wittgenstein's On Certainty, 2004.

${ }^{63}$ Cf. M. Kober, Certainties of a World-Picture, in: H. Sluga and D. G. Stern (eds.), op cit., p. 425.

${ }^{64} \mathrm{O}$ que atestaria, para C. Diamond, Wittgenstein, Mathematics, and Ethics: Resisting the Attractions of Realism, in: H. Sluga and D. G. Stern (eds.), The Cambridge Companion to Wittgenstein, p. 240-241, a contínua importância, para Wittgenstein, em tais escritos tardios, da distinção entre regras/normas de descrição e proposições empíricas descritivas, entre as quais, como entre proposições da lógica (lato sensu) e proposições empíricas, definitivamente não haveria, porém, qualquer fronteira sobejamente explícita.
} 
prática $^{65}$. A associação de certezas a normas ratifica, uma vez mais, a essência lógico-linguística das certezas. Afinal, certezas, como normas constitutivas, tendem a mostrar na linguagem como uso ambas as características de (i) normalidade e (ii) normatividade. E, novamente, isso ajuda a explicar o fenômeno - de sutil e instável linha de demarcação e interconexão, acomodada pelo uso ( $\ddot{U} G$ 98, 318-321, 401402, 460-461, 463-467) - das duplicatas ou Doppelgänger identificado em sentenças como "Esta é a minha mão" e "Isto é azul"66, que, quando desempenham o papel "normativo-constitutivo", não acusam proposições empíricas com valor de verdade determinável, mas um modo de ação ${ }^{67}$. Rigorosamente, apenas esse segundo sentido é decisivo para o sentido de "certeza” que, para Wittgenstein, expõe um recurso lógico-linguístico fundamental com poder de anular a significatividade do jogo-de-linguagem cético. Afinal, no nível normativo, questionar a verdade ou a falsidade é algo que não pode lógico-linguisticamente, portanto significativamente, ser realizado.

\section{CONSIDERAÇÕES FINAIS}

A fundação da operação humana com pensamentos, com a linguagem, é aquilo pelo que certas proposições empíricas podem "estar", e "proposições empíricas", aqui, podem ser tomadas como símbolos para normas constitutivas de práticas, reações fundamentais ou mesmo padrões, diga-se, de qualquer "racionalidade" epistêmica

\footnotetext{
${ }^{65}$ Cf. M. Kober, Certainties of a World-Picture, in: H. Sluga and D. G. Stern (eds.), op. cit., p. 425s.

${ }^{66}$ É perfeitamente possível pensar em circunstâncias em que, por exemplo, "Eu tenho um corpo" é expressão proposicional usada descritivamente, tal como quando um ferido de guerra e vindo de um combate violento, após ser internado e posto em recuperação, revisa a si mesmo e afirma que, apesar de gravemente ferido, manteve, após o exame, o seu corpo ou o corpo e os seus próprios membros, sem transplantes, sem imitações e sem próteses. Mas, possivelmente, a descrição em curso requer a função normativa ora sinalizada, função essa que, ademais, seria de novo apontada quando, em uma aula de línguas, a ostensão e gestos do corpo e/ou de partes do corpo, um uso descritivo, portanto, são usados pelo mestre para ensinar o significado ou para fazer uso correto da palavra "corpo" ( $\ddot{U} G$ 528-531).

${ }^{67}$ Cf. D. Moyal-Sharrock, Understanding Wittgenstein's On Certainty, p. 140-145.
} 
específica ${ }^{68}$. As certezas têm de ser vistas do mesmo modo: não como conhecimento certo ou proposições certas para alguém, mas como fundação de todo o operar humano com pensamentos, como regras ou normas constitutivas de jogos-de-linguagem, dos primitivos aos mais refinados, dos não (relevante ou explicitamente) epistêmicos aos (relevante ou explicitamente) epistêmicos - em particular sobre o mundo exterior. Naturalmente, esse procedimento separa Wittgenstein radicalmente de Moore, na estratégia deste último de refutação ostensiva e, pois, de refutação demonstrativa da falsidade do ceticismo sobre o mundo exterior.

A partir do que foi exposto - e com mais radicalidade -, parece difícil não pensar nas próprias regras em geral como certezas. Apenas é o caso que, a partir da obra Da certeza, o conceito de certeza oportuniza, para o conceito de regras mais antigo, uma estrutura de anterioridade e posterioridade, de primitividade "estrita" e "comum", e orienta a investigação da linguagem na direção de uma reconsideração das próprias regras: ora, elas mesmas, mais antigas na biografia intelectual wittgensteiniana, são suscetíveis a uma tipologia de graduação e prevalência na estruturação da linguagem como uso. As próprias certezas universais e das quais não se pode naturalmente abrir mão podem passar a ser elementos para a formulação de uma teoria de regras como condições de possibilidade da linguagem como uso. Tanto quanto questões epistêmicas têm de se submeter a questões lógicolinguísticas e a epistemologia se submete à linguagem, lembrando que todo agir epistêmico é antes jogo simplesmente, questões de linguagem se submetem a questões epistêmicas em sentido lato. Afinal, regras constitutivas, sendo certezas, parecem facilmente adotar a tipologia de prioridade, primitividade, graduação e prevalência das certezas, tornando-se possível, assim, explicitar quais e como regras se apresentam como condições de possibilidade da linguagem em geral.

\footnotetext{
${ }^{68}$ Com isso, pode-se aproximar "certezas" daquilo que J. Bogen, Wittgenstein and Skepticism, in: S. Shanker (ed.), Ludwig Wittgenstein. Critical Assessments, Vol. 2, p. 322-324, chamou de "capacitadores" (enablers) ou "proposições-E” (E-propositions).
} 


\section{Referências bibliográficas}

AUDI, Robert. Epistemology. A Contemporary Introduction to the Theory of Knowledge. London - New York, Routledge, ${ }^{2} 2003$ (repr. 2004).

BAKER, G. P. and HACKER, P. M. S. Essays on the Philosophical Investigations Volume 1 - Wittgenstein: Meaning and Understanding. Chicago, The University of Chicago Press, 1980.

BLOOR, David. Wittgenstein, Rules and Institutions. London - New York, Routledge, 1997.

BOGEN, James. Wittgenstein and Skepticism. In: SHANKER, Stuart (ed.). Ludwig Wittgenstein. Critical Assessments. Volume 2 (From Philosophical Investigations to On Certainty. Wittgenstein's Later Philosophy). London - New York, 1986 (repr. 1997), p. 317-329.

BOGHOSSIAN, P. The Rule-Following Considerations. In: Mind, 98 (1989), p. 507-549.

BRENNER, William H. Wittgenstein's 'Kantian Solution'. In: MoyalSharrock, Danièle and Brenner, William H. (eds.). Readings of Wittgenstein's On Certainty. Houndmills - New York, Palgrave Macmillan, 2005, p. 122-141.

CAVELL, Stanley. Excursus on Wittgenstein's Vision of Language. In: CAVELL, Stanley. The Claim of Reason. Wittgenstein, Skepticism, Morality, and Tragedy. Oxford, Oxford University Press, 1979, 168-190. . Notes and Afterthoughts on the Opening of Wittgenstein's Investigations. In: SLUGA, Hans and STERN, David G. (eds.). The Cambridge Companion to Wittgenstein. Cambridge, Cambridge University Press, 1996, p. 261-295.

CHILD, William. Wittgenstein. Tradução de Roberto Hofmeister Pich. Porto Alegre, Artmed, 2013.

DALDEGAN DE PÁDUA, Gelson Luiz. O conceito de regras em $D a$ Certeza: terceiro Wittgenstein? Porto Alegre, PUCRS (Dissertação de Mestrado), 2007, 82p. DIAMOND, Cora. C. What Nonsense Might Be. In: DIAMOND, Cora. The Realistic Spirit. Wittgenstein, Philosophy, and the Mind. 
Cambridge, Mass. - London, A Bradford Book (The MIT Press), 1991 (third printing 1996), p. 95-114.

Wittgenstein, Mathematics, and Ethics: Resisting the Attractions of Realism. In: SLUGA, Hans and STERN, David G. (eds.). The Cambridge Companion to Wittgenstein. Cambridge, Cambridge University Press, 1996, p. 226-260.

FOGELIN, Robert J. Wittgenstein. London - New York, Routledge, ${ }^{2} 1987$ (repr. 1996).

. Wittgenstein and Classical Scepticism. In: SHANKER, Stuart (ed.). Ludwig Wittgenstein. Critical Assessments. Volume 2 (From Philosophical Investigations to On Certainty. Wittgenstein's Later Philosophy). London - New York, 1986 (repr. 1997), p. 163-175.

GARVER, Newton. Philosophy as Grammar. In: SLUGA, Hans and STERN, David G. (eds.). The Cambridge Companion to Wittgenstein. Cambridge, Cambridge University Press, 1996, p. 139-170.

GIANNOTTI, J. A. Apresentação do mundo. Considerações sobre o pensamento de Ludwig Wittgenstein. São Paulo, Companhia das Letras, 1995.

GLOCK, Hans-Johann. Wittgenstein Dictionary. Oxford, Blackwell Publishers, 1996 (repr. 1997).

HINTIKKA, Merrill B. und HINTIKKA, Jaakko. Untersuchungen $z u$ Wittgenstein. Übersetzt von Joachim Schulte. Frankfurt am Main, Suhrkamp, 1996.

KIM, Hwa-Kyung. Gewissheit und Skeptizismus bei Wittgenstein. Neue Untersuchungen und Einsichten zu alten Zweifeln. Hamburg, Verlag Dr. Kova , 2006.

KOBER, Michael. Certainties of a World-Picture: The Epistemological Investigations of On Certainty. In: SLUGA, Hans and STERN, David G. (eds.). The Cambridge Companion to Wittgenstein. Cambridge, Cambridge University Press, 1996, p. 411-441.

Gewißheit als Norm: Wittgensteins erkenntnistheoretische Untersuchungen in „Über Gewißheit“. Berlin - New York, Walter de Gruyter, 1993.

. 'In the Beginning was the Deed': Wittgenstein on Knowledge and Religion. In: MOYAL-SHARROCK, Danièle and BRENNER, William H. (eds.). Readings of Wittgenstein's On Certainty. Readings 
of Wittgenstein's On Certainty. Houndmills - New York, Palgrave Macmillan, 2005, p. 225-250.

KREBS, Andreas. Worauf man sich verlässt - Sprach und Erkenntnisphilosophie in Ludwig Wittgensteins „Über Gewissheit“. Würzburg, Königshausen \& Neumann, 2007.

MALCOLM, Norman. George Edward Moore. In: MALCOLM, Norman. Knowledge and Certainty. Essays and Lectures. Englewood Cliffs, Prentice-Hall, 1963, p. 163-183.

. Nothing is Hidden: Wittgenstein's Criticism of his Early Thought. Oxford, Basil Blackwell, 1986.

Wittgenstein: The Relation of Language to Instinctive Behaviour. In: SHANKER, Stuart (ed.). Ludwig Wittgenstein. Critical Assessments. Volume 2 (From Philosophical Investigations to On Certainty. Wittgenstein's Later Philosophy). London - New York, 1986 (repr. 1997), p. 303-318.

MINAR, Edward. Wittgenstein's Response to Scepticism: The Opening of On Certainty. In: MOYAL-SHARROCK, Danièle and BRENNER, William H. (eds.). Readings of Wittgenstein's On Certainty. Houndmills - New York, Palgrave Macmillan, 2005, p. 253-274.

MORAWETZ, Thomas. In: MOYAL-SHARROCK, Danièle and BRENNER, William H. (eds.). Readings of Wittgenstein's On Certainty. Houndmills - New York, Palgrave Macmillan, 2005, p. 165188.

MOYAL-SHARROCK, Danièle. Understanding Wittgenstein's On Certainty. Houndmills - New York, Palgrave Macmillan, 2004.

. Unravelling Certainty. In: MOYAL-SHARROCK, Danièle and BRENNER, William H. (eds.). Readings of Wittgenstein's On Certainty. Houndmills - New York, Palgrave Macmillan, 2005, p. 76-99. MOYAL-SHARROCK, Danièle (ed.). The Third Wittgenstein. The PostInvestigations Works. Aldershot, Ashgate, 2005, 225pp.

MOYAL-SHARROCK, Danièle and BRENNER, William H. (eds.). Readings of Wittgenstein's On Certainty. Houndmills - New York, Palgrave Macmillan, 2005.

PHILLIPS, D. Z. Wittgenstein's On Certainty: The Case of the Missing Propositions. In: MOYAL-SHARROCK, Danièle and BRENNER, 
William H. (eds.). Readings of Wittgenstein's On Certainty. Houndmills - New York, Palgrave Macmillan, 2005, p. 16-29.

PUHL, Klaus. Regelfolgen. In: VON SAVIGNY, Eike (Hrsg.). Ludwig Wittgenstein - Philosophische Untersuchungen. Klassiker Auslegen. Berlin, Akademie, 1998, p. 119-142.

RHEES, Rush. Wittgenstein's On Certainty: There - Like our Life. Edited by D. Z. Phillips. Oxford, Blackwell, 2003.

RÖMPP, Georg. Ludwig Wittgenstein. Eine philosophische Einführung. Köln - Weimar - Wien, Böhlau Verlag - UTB, 2010.

RUDD, Anthony. Wittgenstein, Global Scepticism and the Primacy of Practice. In: MOYAL-SHARROCK, Danièle and BRENNER, William H. (eds.). Readings of Wittgenstein's On Certainty. Houndmills - New York, Palgrave Macmillan, 2005, p. 142-161.

SAMURES, Manuel. Sobre Da certeza de Ludwig Wittgenstein. Um estudo introdutório. Porto, Edições Contraponto, 1994.

SCHULTE, Joachim. Within a System. In: MOYAL-SHARROCK, Danièle and BRENNER, William H. (eds.). Readings of Wittgenstein's On Certainty. Houndmills - New York, Palgrave Macmillan, 2005, p. 59-75.

SLUGA, Hans. Ludwig Wittgenstein: Life and Work - An Introduction. In: SLUGA, Hans and STERN, David G. (eds.). The Cambridge Companion to Wittgenstein. Cambridge, Cambridge University Press, 1996, p. 1-33.

SOSA, Ernest. Knowledge in Perspective: Selected Essays in Epistemology. Cambridge, Cambridge University Press, 1991.

STROLL, Avrum. Moore and Wittgenstein on Certainty. Oxford, Oxford University Press, 1994.

. Why On Certainty Matters. In: MOYAL-SHARROCK, Danièle and BRENNER, William H. (eds.). Readings of Wittgenstein's On Certainty. Houndmills - New York, Palgrave Macmillan, 2005, p. 33-46. WILLIAMS, Michael. Why Wittgenstein Isn't a Foundationalist. In: MOYAL-SHARROCK, Danièle and BRENNER, William H. (eds.). Readings of Wittgenstein's On Certainty. Houndmills - New York, Palgrave Macmillan, 2005, p. 47-58.

WITTGENSTEIN, Ludwig. Philosophische Untersuchungen. In: Idem. Werkausgabe Band 1. Herausgegeben von G. E. M. Anscombe, G. H. 
von Wright und Rush Rhees. Frankfurt a. M., Suhrkamp, ${ }^{10} 1995$, p. 225-580.

Über Gewißheit. In: Idem. Werkausgabe Band 8. Herausgegeben von G. E. M. Anscombe und G. H. von Wright. Frankfurt a. M., Suhrkamp, ${ }^{6} 1994$, p. 113-257. 